\title{
Eğitim bilimleri bölümü öğretim elemanlarının bilişim teknolojisi kullanım becerilerinin geliştirilmesi*
}

\author{
Ayşen BAKİĞGLU* \\ İsmail KARSANTIK ${ }^{* * *}$
}

Özet

$\mathrm{Bu}$ çalışma, öğretim elemanlarının bilişim teknolojisi kullanım becerilerinin geliştirilmesine yönelik Marmara Üniversitesi BAPKO birimine sunulan altyapı projesi kapsamında öğretim elemanlarına verilen eğitim teknolojilerinin kullanımına yönelik eğitimin verimliliğini incelemeyi amaçlamaktadır. Öğretmenlik formasyon derslerini yürüttükleri için Eğitim Bilimleri Bölümü öğretim elemanlarının bilişim teknolojisi kullanma becerileri kazanmaları ve uygulamaları geleceğin öğretmenlerine model olmaları bakımından çok önemlidir. Tarama modelinde gerçekleştirilen araştırmanın çalışma grubunu Marmara Üniversitesi Eğitim Bilimleri Bölümünde görev yapmakta olan öğretim elemanları oluşturmaktadır. Araştırmanın verileri araştırmacılar tarafından geliştirilen ve 7 açık uçlu sorudan oluşan anket aracılığıyla toplanmıştır. Tarama modeline göre tasarlanmış olan bu araştırmada betimsel analiz yöntemi kullanılmıştır. Sonuçlar ise frekans ve yüzdelerle sunulmuştur. Mevcut çalışmada öğretim elemanlarının tablet yardımıyla akıllı tahta kullanımına yönelik aldıkları eğitimin en çok uygulamaya yönelik ihtiyaçlarına cevap verdiği görülürken öğretim elemanlarının sorunlarını gidermeye yönelik olan ihtiyaçlarına verilen cevap minimum düzeyde kalmıştır.

Anahtar kelimeler: Yükseköğretim, akademisyen, profesyonel gelişim, eğitim teknolojisi, akıllı tahta, tablet bilgisayar

* Bu çalışma, Marmara Üniversitesi Bilimsel Araştırma Projeleri (BAPKO) Birimi tarafından desteklenen 5038 no'lu E tipi altyapı projesinden üretilmiştir.

** Prof. Dr., Marmara Üniversitesi, Atatürk Eğitim Fakültesi, Eğitim Bilimleri Bölümü, abakioglu@marmara.edu.tr

*** Arş. Gör., Marmara Üniversitesi, Atatürk Eğitim Fakültesi, Eğitim Bilimleri Bölümü, ismailkarsantik@gmail.com 


\title{
Developing information technology skills of academic staff at the department of educational sciences
}

\begin{abstract}
Purpose of this study is to investigate the efficacy of the in-service training course which promotes the instructional use of the tablet PCs. Since the teaching team of educational science department delivering teaching certificate classes, it is very important lecturers to have technology related knowledge, skills and to practice by exhibiting a model. The tablet PC training program was offered as a part of the infrastructure project, initiated by BAPKO. Participants of the study include the academic staff in the Department of Educational Sciences, Marmara University. Open ended questionnaire developed by researchers is used to collect research data. The findings of the study show that the in-service training caters to the needs which pertain to implementation. On the other hand, the findings of the study indicate that the in-service training program is limited in satisfying the needs of the academic staff.
\end{abstract}

Keywords: Higher education, academics, professional development, educational technology, smart boards, tablet PC

\section{Giriş}

Teknolojinin hızla geliştiği ve bilginin daha hızlı paylaşıldığı çağımız koşullarında hayatımızı daha fazla kolaylaştıracak teknolojinin kullanımına yönelik araştırmalar gün geçtikçe artmaktadır. Yakın geçmişe kadar eğitim-öğretim faaliyetlerini kolaylaştıran kablolu teknolojilerin yerini kablosuz ve mobil teknolojiler almıştır. Kablosuz mobil teknolojinin eğitim bağlamında kullanılmasının önemli nedenlerinden birisi de derslerin pasif olarak doğrudan anlatımı yerine daha eğlenceli, aktif, sosyal ve zengin bir yaşantı sunmasıdır. Günümüz eğitim ortamlarında kullanılan kablosuz mobil teknolojilerinin başında akıllı tahtalar, dizüstü bilgisayarlar ve tablet bilgisayarlar gelmektedir. 2002 yılından bu yana insanların kullanımına açılan tablet bilgisayarlar, kendisini eğitim ve öğretime adamış insanların dikkatini çekmiştir. Yapılandırmacı kuramla birlikte kazandırılan işbirliği ve eşgüdüm kavramlarının daha yoğun bir şekilde kullanılmasına da imkân veren mobil teknolojiler bu sayede önemli birer eğitim aracı haline dönüşmektedir.

Akıllı tahtaların yanında tablet bilgisayarlar da sınıf içi etkileşimin dinamiklerini değiştirebilecek bir potansiyele sahiptir. İnteraktif öğrenme ağları (İÖA), ders veren kişinin ders sırasında derse aktif katılmasını sağlama becerilerini arttıran, hızlı ve anlamlı bir şekilde öğrencilerin değerlendirilmesine fırsat veren, eşzamanlı olarak geribildirimler sağlayarak öğrencilerin öğrenme seviyelerini en üst düzeye çıkaran bir yöntemdir. İnteraktif sınıf ortamı, kablosuz tablet bilgisayarlarının kullanılması ile oluşturulmaktadır (Enriquez, 2010). Öğrenciler ve öğretim elemanlarının sınıf içerisindeki sosyal entegrasyonunun sağlanması bu sayede oldukça kolaylaşmaktadır. 
Yükseköğretimde bilgi ve iletişim teknolojilerinin kullanımı; araştırmacılar, yükseköğretim kurumları ve hükümetler için küresel bir konudur (Kundi ve Nawaz, 2014). Üniversitelerde akıllı tahta ve tablet bilgisayarların kullanımının yaygınlaşması amacıyla öğretim elemanlarına çeşitli eğitimler verilmektedir. Eğitimler sonucunda yaygınlaşan akıllı tahta ve tablet bilgisayar kullanımı çeşitli gereksinimleri de beraberinde getirmiştir. Bunların başında teknik destek ve fakülte desteği gelmektedir. Öğretim elemanlarının kablosuz mobil teknoloji kullanımı sırasında ortaya çıkabilecek sorunları çözebilmek için teknik yardım almaları önemlidir. Bu durum sürdürülebilir eğitim anlayışının da hayata geçmesinde önem arz etmektedir. Kullanımı yaygınlaşan bu tür teknolojiler öğretim elemanlarının yalnızca ders anlatımında değil, karar alma mekanizmalarını harekete geçirmede ve değerlendirme faaliyetlerinde de kullanım kolaylığı sağlamaktadır.

Üniversitelerde teknoloji kullanımının artmasılya yükselen beklentiler yükseköğretimde geleneksel, geleneksel olmayan, uluslararası ve sanal öğrenciler gibi farklı bireyleri bir araya getirerek daha fazla çeşitlenmeyi sağlayacaktır (Kirsebom 1998; akt. Stensaker, Maassen, Borgan, Oftebro ve Karseth, 2007). Bu sebeple günümüzde modern üniversitelerin takip etmesi gereken asıl konu; teknolojinin adapte edilmesi veya teknolojinin sağlayacağı getiriler değil uygulama alanında teknolojinin getirilerinin üniversitelerce ne kadar hızlı farkına varılacağıdır (Eriksen 2001; akt. Stensaker vd., 2007).

Sınıf içerisindeki öğrenme ve öğretme faaliyetlerini desteklemek ve geliştirmek için öğretmenlerce teknolojinin sınıfa adapte edilmesi öğretim uygulamalarının niteliğini arttırmak konusunda büyük etkiye sahiptir. Öğretmenlerin öğretim sürecinde teknolojiyi yeterince etkili olarak kullanmamalarının belgelenmiş olması sebebiyle sınıf içerisinde teknolojinin bütünleşmesine imkân sağlayan faktörlerin veya şartların belirlenmesine yönelik birçok araştırma bulunmaktadır (Hixon ve Buckenmeyer, 2009).

Son zamanlarda kablosuz mobil teknolojiler yükseköğretim kurumlarına katkı sağlamaya başlamıştır. Bu teknoloji çeşidinin insanların eğitim şeklini değiştirme gücü inanılmazdır. Kablosuz mobil teknolojiler, yükseköğretim kurumlarındaki öğrenme ve öğretmenin yeni cephesidir. Bu teknolojiler, eşsiz özelliklerinden ve olumlu etkilerinden dolayı son zamanlarda ve yakın gelecekte birçok eğitim fırsatı sunmuş/sunacaktır. Kablosuz mobil teknolojilerin yükseköğretimde kullanımı artmaya devam edecek ve bu teknolojiler öğrenmenin gerçekleştiği kurumların tercihi olacaktır (Kim, Mims ve Holmes, 2006).

\section{Profesyonel gelişim bağlamında yükseköğretim bölümlerinin gelişimi}

Richards’a (2011) göre öğrenme odaklı liderlik oldukça geniş bir kavramdır. Bu kavram akademisyenlerin sürekli gelişimini, öğrencilerini ve meslektaşlarını öğrenmeye teşvik etmesini içermektedir. Bu sebeple, akademisyenlerin bir diğer uzmanlık alanları da öğrenme olmalıdır. Öğrenme, öğretme ve araştırma yapma akademisyenlerin profesyonel gelişim alanlarını ifade etmektedir.

Yükseköğretim bölümlerinin profesyonel gelişimi farklı biçimlerde devam etmektedir. Profesyonel gelişim süreçleri kariyerler boyunca nadiren istikrarl, tahmin edilebilir ve güvenilir 
bir gidişata sahiptir. Bunun yerine belli bir zaman süresince hızlı, diğer zamanlarda ise durma noktasına gelmektedir (Caffarella ve Zinn, 1999).

\section{Yükseköğretimde bölümlerin profesyonel gelişiminin sürdürülebilirliği}

Yükseköğretimde profesyonel gelişimin sürdürülebilirliği üç eylemi kapsamaktadır: özyönetimli öğrenme, resmi profesyonel gelişim programları ve örgütsel gelişim stratejileri (Cranton, 1994). Profesyonel kariyerde profesyonel gelişim genellikle özyönetim yolunu izlemektedir. Bu tip aktiviteler, aslında zamanımızın büyük bir kısmını oluşturmaktadır. Özyönetimli öğrenme aktiviteleri bireyin kendisinin planladığı, uyguladığı ve değerlendirdiği yaşantılardır. Sınıf materyalleri hazırlama, öğretim yapma, yeni ders programları tasarlama, öğretim programlarını değerlendirme, tez yönetme, araştırma yapma ve sürekli olarak hizmet etmek sonucu gerçekleşen öğrenmeler, özyönetimli profesyonel gelişimin örneklerindendir (Caffarella ve Zinn, 1999).

Örgütsel gelişim ise sürdürülebilir profesyonel gelişimin üçüncü alanıdır. Caffarella (1994) örgütsel gelişimi, örgütün gelişim için, sistematik olarak yapılan değişim çabaları ve eylem stratejilerinin uygulanması olarak tanımlamıştır. Profesyonel gelişimin farklı biçimleri tanımlansa da örgütsel ihtiyaçlara ve konulara değinen örgütün gelişimini amaçlayan profesyonel gelişim biçimi bireyden daha çok örgütün gelişimini amaçlamaktadır. Profesyonel gelişimin bu biçimi genellikle yükseköğretim fakültelerine bağlı merkezi daireler ve yöneticilerce uygulanmaktadır (Wheeler ve Schuster, 1990; akt. Caffarella ve Zinn, 1999).

\section{Yükseköğretimde bölüm gelişimine yönelik görüşler}

Nelson (1983) tarafından tanımlandığı üzere bölüm gelişimi, bölümün performansını arttırmak için tasarlanan; akademisyenlerin, danışmanların, akademik liderlerin ve kurumsal kararlara katılanların profesyonel yaşamının tümüne etki eden çabalardır. Sikes ve Barrett (1976), bölüm gelişiminin amacını "yükseköğretimdeki öğretim faaliyetlerini daha başarılı ve tatmin edici kılmak” olarak tanımlamıştır. Riegle (1987) araştırma bulgusuna dayanarak bölüm gelişimi kavramının farklı açılarını ele almasına rağmen bu kavramın birbiriyle değiştirilebilir olan farklı kavramlarla kullanıldığını belirtmiştir. Bunlar (akt. Camblin ve Steger, 2000):

a) Öğretimsel gelişim: Bölüm gelişiminin öğretimsel boyutunu vurgulamaktadır.

b) Profesyonel gelişim: Her bölümün kendi profesyonel rollerindeki gelişim ve büyümeyi kapsar.

c) Örgütsel gelişim: Bölümün önceliklerini, ihtiyaçlarını ve bölümü öne çıkarır.

d) Kariyer gelişimi: Kariyer gelişimi için gereken hazırlığı vurgular.

e) Kişisel gelişim: Yaşamı planlamayı, kişilerarası iletişim becerilerini ve bölümde bulunan bireylerin kendi gelişimlerini kapsar.

21. yüzyılda başarıyı yakalamak için teknoloji bilgisinin ve becerilerinin öneminin her geçen gün arttığı görülmektedir. Glenn (1997) bilgisayarların basit makinelerden daha karmaşık ve güçlü makinelere dönüşmesi, sınırlı fonksiyonellikten uzaklaşarak karmaşık uygulamalara 
geçişi ve yüksek hızlı ağ bağlantılarını kullanması toplumun diğer kesimini olduğu gibi eğitim kısmını da etkilediğini belirtmiştir. Bilgisayarlar ve internet bu açıdan bakıldığında ABD'deki "PT3 Programı", "Yarının Öğretmenlerini Hazırlama" gibi öğretmenlerin teknolojiyi etkili olarak kullanımına yönelik eğitimsel reform çabalarının ve girişimlerinin odak noktasını oluşturmaktadır. Teknolojiye odaklanmanın esas dayanağı eğitime yönelik olumlu katkı potansiyeline sahip olmasıdır.

Üniversitelerin eğitim bilimleri bölümünün teknoloji kullanımına tarih boyunca kuşkuyla yaklaşılmıştır. ABD'de K-12 okullarının yaygın bir internet ağına ve yeterli bilgisayara sahip olmasına rağmen öğretmenlerin yalnızca üçte birinin bu teknolojiyi kullanıma hazır olduğu görülmüştür (Smerdon, vd., 2000). ABD’de yapılan araştırmalarda birçok ulusal rapor teknoloji kullanımı bakımından öğretmenlerin hazırlıksız olduğunu yansıtmıştır (Panel on Educational Technology, 1997). Belirtilen raporlar öğretmen adaylarını yetiştiren üniversitelerin, teknoloji kullanımını programlarının merkezine almadıklarını vurgulamıştır. Raporlar ayrıca öğretmen eğitimine yönelik hazırlanan öğretim programlarında teknoloji kullanımının az olduğunu ve bölümün profesyonel gelişim olanaklarının yetersiz olduğunu göstermektedir. Bu zorluklarla başa çıkabilmek için profesyonel gelişimine katkı sağlayacak olan bölümün öğretim elemanlarının öğretim ve öğrenme alanında teknolojiye entegrasyonu birçok yükseköğretim kurumunun dikkatini çekmiştir. Araştırmacılar; bölümün gelişimi ve bölüme yardım için alıştırmaların ve desteğin, teknolojinin sınıflara etkili bir şekilde entegrasyonunda önemli bir yere sahip olduğunu vurgulamışlardır (Matthew, Parker ve Wilkinson, 1998; akt. Groves ve Zemel, 2000). Fakat yine de bölümde teknolojinin kullanımını arttırmak için yapılması gereken faktörler belirtilenlerle sınırlı değildir. Bölüm öğretim elemanlarının teknolojiye uyumunun sağlanması için gerekli motivasyon kaynağını sağlamakta kişilerin ihtiyaçları göz önünde bulundurulmalı ve destek için kaynak oluşturma, ödül gibi kurumsal teşvik tedbirleri alınmalıdır (Padgett ve Conceao-Runlee, 2000).

\section{Yükseköğretimde teknolojinin kullanımı}

Skinner (1960), geleneksel eğitim anlayışında yenilikçiliğin eksikliği üzerine vurgu yapmış ve “öğrenen makineler" adlı makalesinde öğrenme sürecinde makinelerin kullanımının öğrencilerin aktif rol oynamasını sağladığını savunmuştur.

Yükseköğretimde teknolojinin adaptasyonuna yönelik motivasyon sağlayan iki etken vardır. Bunlar; teknolojik yeterlilik standartları ve rekabettir. Yükseköğretimde teknolojinin kullanımının en büyük nedeni rekabet gibi görünse de sınıflarda teknoloji kullanımını teşvik eden asıl büyük baskı; hükümetlerin eğitim politikaları ve akreditasyondur (Rogers, 2000).

Yükseköğretimde teknolojinin kullanımının etkilerine bakıldığında; eğitimin yakın ve uzak hedeflerine olumlu katkılar sağladığını görmekteyiz. Fakülte üyelerinin öğrencilere rol model olması ve öğretimde teknolojinin kullanılması öğretmen adayları üzerinde önemli etkiye sahiptir (Parker, 1997). Üniversitelerin öğretmen yetiştiren kurumlar olduğu göz önüne alındığında ilköğretim ve liselerde teknoloji kullanımının yükseköğretimde de teknoloji kullanımını gerektirdiği düşünülmektedir. Bu sebeple özellikle eğitim fakültesi üyelerinin teknolojiye 
adaptasyonu kilit rol oynamaktadır. Bu gerekliliğe cevaben üniversiteler öğrencilerinin mezuniyet gereklerinin bir parçası olarak teknolojinin kullanımının yeterliliği üzerinde durmaya başlamıştır (Davis, 1989). Üniversitelerin rekabetçi anlayışı yeniliklerin uygulanması adına üniversitelere lokomotif görevi vermektedir (Rogers, 2000).

Teknolojinin kullanımı bilginin paylaşımını, daha kolay ve etkili bir şekilde aktarılmasını sağlamaktadır. Üniversitelerde teknolojinin kullanımı ile yapılacakların bir kısmını Diaz ve McGee (2007) şu şekilde sıralamıştır (Oostveen, Muirhead ve Goodman, 2011):

- Çeşitli öğrencilere derslerde yardımcı olabilecek ek sunumlar yapmalarına imkân sağlar.

- Ders esnasında öğrencilerin sınıf yönetiminde rol oynayan; yazılı sınav, test, tartışma, sohbet gibi yöntemleri kullanmalarını sağlar.

- Öğrencilerin derslerinde yardımcı olabilecek ücretsiz internet araçlarını kullanmalarının önünü açar.

- Tablette kelime işlemci programlarını kullanarak hazırlanılan çalışmaların gösterimine imkân verir.

- Konu ile ilgili sanal grup çalışmalarına izin verir ve güncel başlıkla ilgili görsellik sağlar.

- Öğrencilere yönelik ders içi öğrenme durumları oluşturarak çeşitli firsatlar sunar.

Öğrencilerin diğer öğrencilerle ve öğretim elemanlarıyla aktif tartısmaya katılması veya yine aynı kişilerin işbirliğiyle problem çözme sürecine dâhil olması onların öğrenmelerini önemli şekilde geliştirmektedir (Tront, 2007). Prince ve Felder (2007), öğrencilerin öğrenmesinde önem arz eden temel durumun öğrencilerin öğrenme sürecine aktif katılımının sağlanması olduğunu belirtmiştir. Hake (1998), 6000'den fazla öğrenciden toplanan ön test ve son test verilerine dayanarak interaktif öğrenme ortamlarının öğrencilerin öğrenmesi üzerinde önemli katkı sağladığını ifade etmiştir.

Yaklaşık 10 yıllık e-öğrenme ortamı incelendiğinde, teknolojinin üniversitelerdeki öğrenme ortamlarında önemli değişikliklere imza attığı görülmektedir. Özellikle Avrupa’da ve İsviçre’de 1990’ların sonunda başlatılan hükümet programları eğitim teknolojilerinin potansiyelinin artmasını sağlamıştır. ABD'de bu alanda başlatılan ilk incelemeler göstermiştir ki; eğitim teknolojilerinin yükseköğretimde öğretim elemanlarınca kullanımı sırasında Avrupa ülkelerinin çoğunun yaşadığı benzer sorunlarla karşılaşılmıştır. Bu sorunlardan ilki hayat boyu öğrenmeyi destekleyen üniversitelerin fakülte üyelerinin teknolojiye adaptasyonu sürecinde gösterdikleri dirençtir. Bu sebeple Moser (2007) fakültenin içinde bulunduğu süreci yönlendiren değişkenlere odaklanarak öğretim üyelerinin bu davranışı altında yatan nedenlere odaklanmıştır. Öğretim üyelerinin teknolojiye uyumu konusunda önemli hususlara değinen ve ilk olarak fakültenin, öğretim elemanlarının teknolojiye uyumunu desteklemesi gerektiğine inanan Moser (2007), uyum için harcanan zamanın da temel teşkil ettiğini belirtmiştir. Moser (2007) ayrıca, öğretim elemanlarının teknolojiye uyumunun stratejik bir seviyede gerçekleşmesi gerektiğini vurgulamış ve profesyonel teknolojik desteğin de işlenecek dersin kalitesini arttırması bakımından önemli 
olduğunu belirtmiştir. Moser (2007) bu çalışmasında şu tavsiyelerde bulunmuştur:

- Sürekli ihtiyaç analizi yapılmalı,

- Bireylerin ve grupların becerilerini öne çıaran iyi prova edilmiş örnek dersler yapılmalı,

- Bireyin danışmasına imkân veren mükemmel ve faydalı bir süreç uygulanmalı,

- Eşgüdümü ve birlikte çalışmayı gerektiren daha fazla ve geniş çaplı projeler uygulanmalı,

- Çok yönlü değerlendirme eylemlerinde bulunulmalıdır.

Moser (2007), öğretim elemanlarının teknolojiye uyum döngüsünü Şekil l'de belirtmiştir.

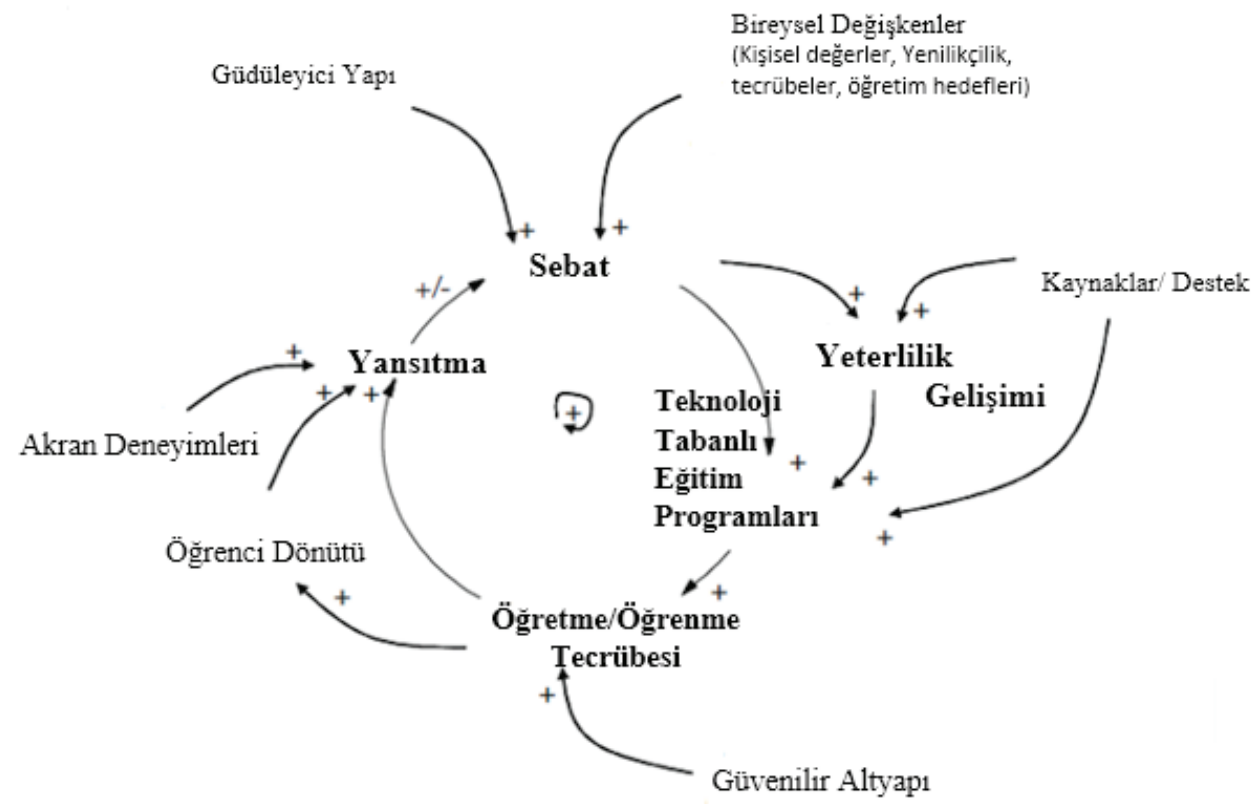

Şekil I. Öğretim elemanlarının teknolojiye uyum döngüsü

Öğretim elemanlarının sınıf içerisinde teknolojiye neden ve nasıl uyum sağlayacağına ilişkin çok farklı çerçeveler bulunmaktadır. Davis (1989) teknoloji kabul modelinde öğretim elemanlarının teknolojiye uyumu konusuna dikkat çekmiş ve modelin iki farklı değişkene sahip olduğunu belirterek bunları; algılanan kullanışlılık ve algılanan kullanım rahatlığı olarak tanımlamıştır. Yine aynı modelde belirtilen iki değişkenin öğretim elemanlarının teknolojiyi kabulünde önemli rol oynadığını göstermektedir.

Tablet bilgisayarlar bilginin kalem kullanılarak elektronik ortama aktarımını sağlayan teknolojidir. Tablet bilgisayarlarla yazım "kalem tabanlı bilgisayar" ve "dijital imzalama" olarak da bilinmektedir. Tablet bilgisayarlar ikiye ayrılmaktadır. Bunlar; farklı durumlara uygun olarak farklı şekillere girebilen ve dönüştürülemeyen yalnızca ekranın üzerinde işlem yapmaya olanak 
sağlayan bilgisayarlardır. Dönüştürülebilen tablet bilgisayarlar bir klavyeye eklenmiş, 180 derece dönebilen ve tamamen düz bir yüzey haline gelebilen bilgisayarlardır. Diğer tablet bilgisayar ise yalnızca ekranın üzerine yazıma izin veren bilgisayarlardır. Bu tip tablet bilgisayarlar çok hafif olmasına rağmen klavyesiz olması dolayısıyla fonksiyonellik bakımından dezavantajlıdır. Fakat bazı modeller klavye kullanımına imkân vererek bu dezavantajı bir avantaja dönüştürebilmektedir (Steinweg, Williams ve Stapleton, 2010).

Tablet bilgisayarlar çok farklı bilgi giriş seçenekleri sunmaktadır. Bilginin ekrana kalem kullanılarak el yazısıyla yazılması halinde bu yazının hem dijital imza olarak hem de standart yazı tipine dönüştürülerek saklanmasına imkân vermektedir. Yazının farklı şekillerde saklanmasının yanında ses tanıma programlarının da tablet bilgisayarlara büyük bir avantaj getirdiği görülmektedir (Steinweg, Williams ve Stapleton, 2010).

Tabletbilgisayarlar, dizüstü bilgisayarların sağladığıimkânlara sahip olabilmektedir. Geleneksel kelime işlemci programları ve üretim için gerekli farklı programları çalıştırabilmektedir. Backon (2006) kalem kullanmanın sağladığı önemli öğrenme fonksiyonlarının tablet PC ile daha da ileri götürülebileceğini belirtmektedir (Steinweg, Williams ve Stapleton, 2010).

Tablet bilgisayarların kullanımı ilk olarak sağlık, sigortacılık, kamu güvenliği ve emlak piyasasında kullanılsa da bu tip bilgisayarların bir sonraki yükselişini yükseköğretimde yapacağını düşünülmektedir. Özellikle geçtiğimiz iki ylllık süre içerisinde üniversite öğrencilerinin tablet PC kullanımı konusunda çok fazla çaba harcadıkları görülmüștür. Bunun sebebi aktif sanal öğrenme platformları kurulmasıyla artan öğrenme teknikleri ve öğrenci-öğrenci ve öğrenci-öğretim elemanı işbirliğidir (Weaver ve Prey, 2007). Keengwe, Kidd ve Kyei-Blankson (2009) öğretim elemanlarının öğretim faaliyetlerinin teknolojiye entegrasyonunun sağlanmasının ve öğretim sürecine ait çıktıların teknoloji kullanımıyla yeniden şekillendirmenin gerekli olduğunu ifade etmektedir.

\section{Yöntem}

Öğretim elemanlarının bilişim teknolojisi kullanım becerilerinin geliştirilmesine yönelik yapılan E tipi altyapı projesi (M.Ü. BAPKO, 2015-5038 no'lu) kapsamında, öğretim elemanlarına eğitim teknolojilerinin kullanımına yönelik verilen eğitimin verimliliğini incelemeyi amaçlayan bu araştırma tarama modeline göre tasarlanmıştır. Tarama modelleri, mevcut durumu olduğu gibi betimlemeyi amaçlamaktadır (Karasar, 2013)

Araştırmanın çalışma grubunu Marmara Üniversitesi Eğitim Bilimleri Bölümünde görev yapmakta olan öğretim elemanları oluşturmaktadır. Araştırmacılar tarafından geliştirilen ve yedi açık uçlu sorudan oluşan anket formu eğitimden önce ve sonra uygulanmıştır. Çalışma kapsamında toplanan verilerin analizinde betimsel analiz kullanılmıştır. Veriler tablolar halinde frekans ve yüzdeler verilerek sunulmuştur. 


\section{Bulgular}

$\mathrm{Bu}$ bölümde, araştırmadan elde edilen bulgulara yer verilmiştir. Öğretim elemanlarının öğretim teknolojilerinin kullanımına yönelik verilecek olan eğitim öncesinde uygulanan anketlerden edinilen ön uygulama ve son uygulamanın frekans bilgileri ve yüzde değerleri aşağıdaki tablolarda yer almaktadır.

Tablo I

Öğretim Elemanlarının Tablet Bilgisayar Yardımıla Akıllı Tahta Kullanımı Bilgi Beceri Düzeyi

\begin{tabular}{|l|c|c|c|c|c|c|c|c|c|}
\hline \multirow{2}{*}{} & & \multicolumn{2}{|c|}{ Çok İyi } & \multicolumn{2}{|c|}{ İyi } & \multicolumn{2}{c|}{ Orta } & \multicolumn{2}{|c|}{ Kötü } \\
\cline { 2 - 11 } & $\mathrm{f}$ & $\%$ & $\mathrm{~F}$ & $\%$ & $\mathrm{f}$ & $\%$ & $\mathrm{f}$ & $\%$ \\
\hline $\begin{array}{l}\text { Tablet bilgisayar } \\
\text { yardımıla akıllı tahta } \\
\text { kullanımı bilgi beceri } \\
\text { düzeyi }\end{array}$ & Ön uygulama & 7 & 18,4 & 15 & 39,4 & 14 & 36,8 & 2 & 5,2 \\
\cline { 2 - 11 } & Son uygulama & 2 & 11,8 & 5 & 29,4 & 10 & 58,8 & 0 & 0 \\
\hline
\end{tabular}

Öğretim elemanlarının tablet bilgisayar kullanma bilgi ve beceri düzeyi ön uygulama sonuçları Tablo 1'den incelendiğinde 7 (\%18,4) öğretim elemanı çok iyi düzeyde, 15 (\%39,4) öğretim elemanı iyi düzeyde, $14(\% 36,8)$ öğretim elemanı ise orta düzeyde, $2(\% 5,2)$ öğretim elemanı ise kötü düzeyde tablet bilgisayar kullandıklarını ifade ettikleri görülmektedir.

Öğretim elemanlarının tablet bilgisayar kullanma bilgi ve beceri düzeyi son uygulama sonuçları incelendiğinde iki $(\% 11,8)$ öğretim elemanı çok iyi düzeyde, beş $(\% 29,4)$ öğretim elemanı iyi düzeyde, $10(\% 58,8)$ öğretim elemanı ise orta düzeyde tablet bilgisayar kullandıklarını ifade ederken hiçbir öğretim elemanı kötü düzeyde tablet bilgisayar kullandığını ifade etmemiştir.

Tablo 2

Öğretim Elemanlarinın Eğitime Duydukları Ihtiyaç

\begin{tabular}{|l|c|c|c|c|c|c|c|}
\hline \multirow{2}{*}{} & & \multicolumn{2}{|c|}{ Evet } & \multicolumn{2}{c|}{ Hayır } & \multicolumn{2}{c|}{ Kararsız } \\
\cline { 3 - 8 } & $\mathrm{f}$ & $\%$ & $\mathrm{f}$ & $\%$ & $\mathrm{f}$ & $\%$ \\
\hline \multirow{2}{*}{$\begin{array}{l}\text { Eğitime duyulan } \\
\text { ihtiyaç }\end{array}$} & Ön uygulama & 6 & 15,7 & 27 & 71 & 5 & 13,1 \\
\cline { 2 - 8 } & Son uygulama & 11 & 64,7 & 5 & 29,4 & 1 & 5,9 \\
\hline
\end{tabular}

Öğretim elemanlarının akıllı tahta ve tablet bilgisayar kullanımına yönelik eğitime duyduğu ihtiyaçların ön uygulama sonuçları incelendiğinde $6(\% 15,7)$ öğretim elemanının akıllı tahta ve 
tablet bilgisayar kullanımına yönelik eğitime ihtiyaç duyduğu, 27 (\%71) öğretim elemanın ihtiyaç duymadığı ve $5(\% 13,1)$ öğretim elemanının ise kararsız kaldığı sonucuna ulaşılmıştır.

Öğretim elemanlarının akıllı tahta ve tablet bilgisayar kullanımına yönelik eğitime duyduğu ihtiyaçların son uygulama sonuçları incelendiğinde ise $11(\% 64,7)$ öğretim elemanının akıllı tahta ve tablet bilgisayar kullanımına yönelik eğitime ihtiyaç duyduğu, $5(\% 29,4)$ öğretim elemanının ihtiyaç duymadığı, $1(\% 5,9)$ öğretim elemanının ise kararsız kaldığı sonucuna ulaşılmıştır.

Tablo 3

Öğretim Elemanlarının Öğretici Olmaya Gönüllülüğ̈̈

\begin{tabular}{|l|c|c|c|c|c|c|c|}
\hline \multirow{2}{*}{} & & \multicolumn{2}{|c|}{ Evet } & \multicolumn{2}{c|}{ Hayır } & \multicolumn{2}{c|}{ Kararsız } \\
\cline { 3 - 8 } & & $\mathrm{f}$ & $\%$ & $\mathrm{f}$ & $\%$ & $\mathrm{f}$ & $\%$ \\
\hline \multirow{2}{*}{$\begin{array}{l}\text { Öğretici olmaya } \\
\text { gönüllülük }\end{array}$} & Ön uygulama & 6 & 15,7 & 27 & 71 & 5 & 13,1 \\
\cline { 2 - 8 } & Son uygulama & 2 & 11,8 & 14 & 82,4 & 1 & 5,9 \\
\hline
\end{tabular}

Öğretim elemanlarının tablet bilgisayar yardımıyla öğretim yapma konusunda öğretici olma durumları ön uygulama sonuçları incelendiğinde $6(\% 15,7)$ öğretim elemanının öğretici olmak istediği, 27 (\%71) öğretim elemanının öğretici olmak istemediği ve $5(\% 13,1)$ öğretim elemanının öğretici olma konusunda kararsız olduğu sonucuna ulaşılmıştır.

Öğretim elemanlarının tablet bilgisayar yardımıyla öğretim yapma konusunda öğretici olma durumları son uygulama sonuçları incelendiğinde, $2(\% 11,8)$ öğretim elemanının öğretici olmak istediği, 14 (\%82,4) öğretim elemanının öğretici olmak istemediği ve $1(\% 5,9)$ öğretim elemanının öğretici olma konusunda kararsız olduğu sonucuna ulaşılmıştır.

Tablo 4

Öğretim Elemanlarının Öğretim Teknolojileri Kullanımına Yönelik Eğitimden Beklentileri

\begin{tabular}{|l|c|c|c|c|c|c|c|c|c|}
\hline & & \multicolumn{2}{|c|}{$\begin{array}{c}\text { Uygulamaya } \\
\text { Dönük Kullanım }\end{array}$} & \multicolumn{2}{|c|}{ Teknik Destek } & \multicolumn{2}{|c|}{$\begin{array}{c}\text { İleri Düzey } \\
\text { Kullanım }\end{array}$} & \multicolumn{2}{c|}{ İhtiyaç Yok } \\
\cline { 3 - 11 } & & $\mathrm{f}$ & $\%$ & $\mathrm{f}$ & $\%$ & $\mathrm{f}$ & $\%$ & $\mathrm{f}$ & $\%$ \\
\hline & Ön uygulama & 23 & 60,5 & 1 & 2,6 & 10 & 26,3 & 4 & 10,5 \\
\hline $\begin{array}{l}\text { Eğitimden } \\
\text { beklentiler }\end{array}$ & Son uygulama & 12 & 70,5 & 1 & 5,9 & 3 & 17,6 & 1 & 5,9 \\
\hline
\end{tabular}


Öğretim elemanlarının öğretim teknolojileri kullanımına yönelik eğitimden beklentilerini incelemek üzere yapılan ön uygulama sonuçları Tablo 4’te görüldüğü üzere $23(\% 60,5)$ öğretim elemanının derste aktif olarak kullanma ihtiyacına, bir $(\% 2,6)$ öğretim elemanının sorunlarını gidermeye yönelik olan ihtiyaçlarına, 10 (\%26,3) öğretim elemanının ileri düzey ihtiyaçlarına cevap vereceği, dört $(\% 10,5)$ öğretim elemanının ise herhangi bir ihtiyaç belirtmediği sonucuna ulaşılmıştır. Ayrıca öğretim elemanlarına, verilen eğitime yönelik önerileri de sorulmuş ve üç kişinin öğretim elemanının eğitimin uygulama ağırlıklı olmasını beklediği, bir öğretim elemanının ön hazırlık yapılması gerektiğini belirttiği, bir öğretim elemanının teknik donanımın düzenlenmesi gerektiğini belirttiği, bir öğretim elemanın ise farklı branşlara yönelik eğitimler düzenlenmesi gerektiğini vurguladıkları sonucuna ulaşılmıştır.

Öğretim elemanlarının öğretim teknolojilerinin kullanımına yönelik eğitimden beklentilerine yönelik son uygulama sonuçları incelendiğinde $12(\% 70,5)$ öğretim elemanının derste aktif olarak kullanma ihtiyacına, bir $(\% 5,9)$ öğretim elemanını sorunlarını gidermeye yönelik olan ihtiyaçlarına, üç $(\% 17,6)$ öğretim elemanının ileri düzey ihtiyaçlarına cevap verdiği, bir $(\% 5,9)$ öğretim elemanının ise herhangi bir ihtiyaç belirtmediği sonucuna ulaşılmıştır.

Tablo 5

Öğretim Teknolojilerinin Kullanımına Yönelik Verilen Eğitimin Etkililĭgi

\begin{tabular}{|l|c|c|c|c|c|}
\hline \multirow{2}{*}{} & \multirow{2}{*}{} & \multicolumn{2}{|c|}{ Evet } & \multicolumn{2}{|c|}{ Hayır } \\
\cline { 3 - 6 } & & $\mathrm{f}$ & $\%$ & $\mathrm{f}$ & $\%$ \\
\hline \multirow{3}{*}{ Eğitimin etkililiği } & Ön uygulama & 22 & 62,8 & 13 & 37,1 \\
\cline { 2 - 6 } & Son uygulama & 13 & 76,5 & 4 & 23,5 \\
\hline
\end{tabular}

Tablo 5’te görüldüğü üzere araştırma kapsamındaki öğretim elemanlarının öğretim teknolojilerinin kullanımına yönelik verilecek eğitimin etkililiğinin ön uygulama sonuçları incelendiğinde $22(\% 62,8)$ öğretim elemanının algısal anlamda verilecek eğitimin etkili olacağına yönelik, $13(\% 37,1)$ öğretim elemanının ise verilecek eğitimin etkili olmayacağına yönelik inancının olduğu sonucuna ulaşılmıştır.

Öğretim elemanlarının öğretim teknolojilerinin kullanımına yönelik verilen eğitimin etkililiğinin son uygulama sonuçları incelendiğinde; 13 (\%76,5) öğretim elemanın verilen eğitimin etkililiğinden memnun kaldığı, dört $(\% 23,5)$ öğretim elemanın memnun kalmadığ 1 sonucuna ulaşılmıştır. 
Tablo 6

Öğretim Elemanlarının Tablet Bilgisayar Yardımıyla Akıllı Tahta Kullanarak Öğretim Yapma Durumu

\begin{tabular}{|l|c|c|c|c|c|c|c|}
\hline \multirow{2}{*}{} & & \multicolumn{2}{|c|}{ Evet } & \multicolumn{2}{c|}{ Hayır } & \multicolumn{2}{c|}{ Kararsiz } \\
\cline { 3 - 8 } & & $\mathrm{f}$ & $\%$ & $\mathrm{f}$ & $\%$ & $\mathrm{f}$ & $\%$ \\
\hline \multirow{2}{*}{$\begin{array}{l}\text { Tablet bilgisayar } \\
\text { yardımiyla akıllı } \\
\text { tahta kullanimı }\end{array}$} & Ön uygulama & 22 & 57,8 & 13 & 34,2 & 3 & 7,8 \\
\cline { 2 - 8 } & Son uygulama & 7 & 41,2 & 10 & 58,8 & 0 & 0 \\
\hline
\end{tabular}

Öğretim elemanlarının tablet bilgisayar yardımıyla akıllı tahta kullanarak öğretim yapma konusunda yapılan ön uygulama sonuçları Tablo 6'da görüldüğü üzere $22(\% 57,8)$ öğretim elemanının istekli olduğu, 13 (\%34,2) öğretim elemanının isteksiz olduğu ve üç $(\% 7,8)$ öğretim elemanının ise kararsız olduğu sonucuna ulaşılmıştır.

Öğretim elemanlarının tablet bilgisayar yardımıyla akıllı tahta kullanarak öğretim yapma konusunda yapılan son uygulama sonuçları incelendiğinde yedi $(\% 41,2)$ öğretim elemanının istekli olduğu, $10(\% 58,8)$ öğretim elemanının ise isteksiz olduğu sonucuna ulaşılmıştır.

Tablo 7

Öğretim Elemanlarının Örnek Ders Verme İsteği

\begin{tabular}{|l|c|c|c|c|c|c|c|}
\hline \multirow{2}{*}{} & & \multicolumn{2}{|c|}{ Evet } & \multicolumn{2}{c|}{ Hayır } & \multicolumn{2}{c|}{ Karars1z } \\
\cline { 3 - 8 } & & $\mathrm{f}$ & $\%$ & $\mathrm{f}$ & $\%$ & $\mathrm{f}$ & $\%$ \\
\hline \multirow{2}{*}{$\begin{array}{l}\text { Örnek ders } \\
\text { verme isteği }\end{array}$} & Ön uygulama & 1 & 4,3 & 19 & 82,6 & 3 & 13 \\
\cline { 2 - 8 } & Son uygulama & 2 & 11,8 & 14 & 82,4 & 1 & 5,9 \\
\hline
\end{tabular}

Öğretim elemanlarının tablet bilgisayar yardımıyla akıllı tahta kullanarak örnek bir ders verme istekliliğine ilişkin ön uygulama sonuçları Tablo 7’de görüldüğü üzere bir $(\% 4,3)$ öğretim elemanının istekli olduğu, 19 (\%82,6) öğretim elemanın istekli olmadığı, üç (\%13) öğretim elemanının ise herhangi bir görüş belirtmediği sonucuna ulaşılmıştır.

Öğretim elemanlarının tablet bilgisayar yardımıyla akıllı tahta kullanarak örnek bir ders verme istekliliğine ilişkin son uygulama sonuçları incelendiğinde $2(\% 11,8)$ öğretim elemanının istekli olduğu, $14(\% 82,4)$ öğretim elemanının istekli olmadığı, $1(\% 5,9)$ öğretim elemanının ise herhangi bir görüş belirtmediği sonucuna ulaşılmıştır. 


\section{Tartışma, sonuç ve öneriler}

Öğretim elemanlarının bilişim teknolojisi kullanım becerilerinin geliştirilmesi için yapılan altyapı projesi kapsamında öğretim elemanlarına verilen eğitim teknolojilerinin kullanımına yönelik eğitimin etkililiğini değerlendirmeyi amaçlayan bu çalışmanın, öğretim elemanlarının tablet yardımıyla akıllı tahta kullanma becerilerinin geliştirilmesi hususunda önemli rol oynadığı sonucuna ulaşılmıştır. Öğretim elemanlarının tablet yardımıyla akıllı tahta kullanarak öğretim yapma bilgi ve beceri düzeyinin arttığı görülmüştür. Rienties, Brouwer ve Lygo-Baker (2013), 73 akademisyen ile yaptığı araştırmada uygulanan eğitimin katılımcıların öğretim bağlamında teknoloji kullanımı bilgi ve beceri düzeylerinin anlamlı düzeyde arttı̆̆g sonucuna ulaşmışlardır. Bu bağlamda iki çalışmanın sonuçları itibariyle benzerlik gösterdiği görülmektedir. Bu durum öğretim elemanlarına verilen eğitim teknolojilerinin kullanımına yönelik eğitimlerin, öğretim elemanlarının eğitim teknolojilerini kullanma bilgi ve beceri düzeylerinin anlamlı düzeyde arttırdığını göstermektedir.

Çalışmadan ortaya çıkan bir diğer sonuç ise öğretim elemanlarının tablet yardımıyla akıllı tahta kullanımına yönelik daha fazla eğitime ihtiyaç duyduklarını düşünmeleridir. Hogue (2013), yükseköğretim düzeyinde verilen eğitimlerin tablet bilgisayarlarla desteklenmesi profesyonel geliş̧imin sürekliliği açısından önemli olduğunu belirtmiştir. Bu çalışmada da yükseköğretimde eğitim teknolojilerinin kullanımına yönelik verilen eğitimlerin devamlılığının önemli olduğu vurgulanmıştır. Bu bağlamda mevcut çalışmanın bulguları literatürü destekler niteliktedir.

Rienties, Brouwer ve Lygo-Baker (2013), birçok akademisyenin teknolojiye adapte olma konusunda isteksiz olduğunu belirtmektedir. Mevcut çalışmada tablet yardımıyla öğretim konusunda öğretim elemanlarına öğretici olma istekliliği incelendiğinde birçok öğretim elemanının öğretici olma konusunda isteksiz olduğu görülmüştür. Bu durum mevcut çalışmanın batı literatürü ile uyumlu olduğunu yansitmaktadır.

Öğretim elemanlarının tablet yardımıyla akıllı tahta kullanımına yönelik aldıkları eğitimin en çok uygulamaya yönelik ihtiyaçlarına cevap vermesini istedikleri görülmektedir. Perlman, Christner, Ross ve Lypson (2014), e-portfolyo değerlendirme aracının uygulanmasına ilişkin geliştirdikleri öğretim elemanlarının bilgi ve becerilerinin geliştirilmesine yönelik programda uygulamaya ağırlık verilmiştir. Musarrat ve Williams (2013) eğitim teknolojilerinin öğretim elemanları tarafından kabul görüp kullanılması için sebatın önemi üzerine vurgu yapmaktadır. Bu bağlamda verilen eğitimlerin uygulama odaklı olmasına değer verildiği görülmektedir.

Tablet yardımıyla akıllı tahta kullanımına yönelik verilen önceki eğitimlerin yararlı olduğu mevcut çalışmanın sonuçları arasındadır. Weber (2013), öğretim elemanlarının gelişim düzeylerini incelediği çalışmasında eğitim teknolojilerinin kullanımına yönelik eğitimlere daha fazla katılan öğretim elemanlarının eğitim teknolojilerini kullanımının katılmayanlara oranla üst düzeyde olduğunu ortaya koymuştur. Benzer şekilde Drouin, Vartanian ve Birk (2014), öğretim elemanlarının tablet bilgisayarların kullanmalarına yönelik geliştirdikleri uygulama modelinin etkili olduğu sonucuna ulaşmıştır. Bu bakımdan çalışmaların bulguları benzerlik göstermektedir. 
$\mathrm{Bu}$ çalışmada, öğretim elemanlarının ders dışı zamanlarda tablet bilgisayar yardımıyla akıllı tahta kullanımına yönelik bilgi beceri düzeylerini arttırma imkânı bulamadıkları ortaya konulmuştur. Yeni edinilen becerilerin kalıcılığının sağlanması için uygulamaya yönelik firsatların verilmesi gerekmektedir (Perlman, Christner, Ross ve Lypson, 2014). Bu bağlamda beceri eğitiminin sağlanabilmesi için kuramsal bilginin uygulamaya konulması gerekliliği her iki çalışmanın da ortak noktasını oluşturmaktadır.

$\mathrm{Bu}$ çalışmada, öğretim elemanlarının birbirlerinin profesyonel gelişimlerine katkıda bulunmak amacıyla örnek ders vermek için istekli olmadıkları sonucuna ulaşılmıştır. Rienties, Brouwer ve Lygo-Baker (2013) çalı̧̧malarında yükseköğretimde eğitim teknolojilerinin kullanımına yönelik uygulanan programda öğretim elemanlarının bilgi ve beceri düzeylerinin anlamlı olarak yükseldiğini ve uygulanan programdan önce öğretim elemanlarının eğitim teknolojilerinin kullanımı konusunda isteksiz olduğunu belirtmiştir. Bu açıdan bakıldığında eğitim teknolojilerinin kullanımına yönelik uygulanan programların öğretim elemanlarının yalnızca becerilerini değil tutumlarını da olumlu yönde etkilemeye odaklanması gerektiği söylenebilir.

$\mathrm{Bu}$ çalışmadan elde edilen bulgular neticesinde aşağıdaki öneriler sunulmuştur:

- Eğitim öncesi eğitim teknolojisi uzmanlarınca bir ihtiyaç analizi yapılıp o doğrultuda eğitim düzenlenmesi verilen eğitimlerin etkililiğini arttırabilir.

- Eğitimlerin uygulamaya dönük ve periyodik yapılması halinde eğitimin etkililiği arttırabilir, eğitimler devam ettirilerek etkileri uzun süreli olarak incelenebilir.

- Makale konusu karma yöntemle çalışılabilir. 


\section{Kaynaklar}

Caffarella, R. S. \& Zinn, L. F. (1999). Professional development for faculty: A conceptual framework of barriers and supports. Innovative Higher Education, 23(4), 241-254.

Camblin, L. D. \& Steger, J. A. (2000). Rethinking faculty development. Higher Education, 39(1), 1-18.

Cranton, P. (1994). Self-directed and transformative instructional development. The Journal of Higher Education, 726-744.

Davis, F. D. (1989). Perceived usefulness, perceived ease of use and user acceptance of information technology. MIS Quarterly, 319-340.

Drouin, M., Vartanian, L. R. \& Birk, S. (2014). A community of practice model for introducing mobile tablets to university faculty. Innovative Higher Education, 39(3), 231-245.

Enriquez, A. G. (2010). Enhancing student performance using tablet computers. College Teaching, 58, 77-84.

Glenn, A. D. (1997). Technology and the continuing education of classroom teachers. Peabody Journal of Education, 72(1), 122-128.

Groves, M. M. \& Zemel, P. C. (2000). Instructional technology adoption in higher education: An action research case study. International Journal of Instructional Media, 27(1), 54-61.

Hake, R. R. (1998). Interactive-engagement versus traditional methods: A six-thousand-student survey of mechanics test data for introductory physics courses. American journal of Physics, 66(1), 64-74.

Hixon, E. \& Buckenmeyer, J. (2009). Revisiting technology integration in schools: Implications for professional development. Computers in the Schools, 26(2), 130-146.

Hogue, R. J. (2013). Considerations for a professional development program to support iPads in higher education teaching. Ubiquitous Learning: An International Journal, 5(1), 25-35.

Keengwe, J., Kidd, T. \& Kyei-Blankson, L. (2009). Faculty and technology: Implications for faculty training and technology leadership. Journal of Science Education and Technology, 18(1), 23-28.

Karasar, N. (2013). Bilimsel araştırma yöntemleri (25. baskı). Ankara: Nobel Yayınları

Kim, S. H., Mims, C. ve Holmes, K. P. (2006). An introduction to current trends and benefits of mobile wireless technology use in higher education. AACE Journal, 14(1), 77-100.

Kundi, G. M., \& Nawaz, A. (2014). From e-learning 1.0 to e-learning 2.0: Threats \& opportunities for higher education institutions in the developing countries. European Journal of Sustainable Development, 3(1), 145-160. Doi: 10.14207/ejsd.2014.v3n1p145.

Moser, F. Z. (2007). Faculty adoption of educational technology. EDUCAUSE Quarterly, 30(1), 66.

Musarrat, M. \& Williams, B. (2013). Enablers and barriers to academic's acceptance of technology: can "Individual differences" make a difference? Electric Dreams: Proceedings Ascilite, 607-611.

Padgett, D. L. \& Conceao-Runlee, S. (2000). Designing a faculty development program on technology: If you build it, will they come? Journal of Social Work Education, 36(2).

Panel on Educational Technology. (1997). Report to the President on the use of technology to strengthen K-12 education in the United States. Washington, D.C.: President's Committee of Advisors on Science and Technology.

Parker, D. R. (1997). Increasing faculty use of technology in teaching and teacher education. Journal of Technology and Teacher Education, 5, 105-116.

Perlman, R. L., Christner, J., Ross, P. T. \& Lypson, M. L. (2014). A successful faculty development program for implementing a sociocultural e-Portfolio assessment tool. Academic Medicine, 89(2), 257-262.

Prince, M. \& Felder, R. (2007). The many faces of inductive teaching and learning. Journal of College Science Teaching, 36(5), 14.

Richards, D. (2011). Leadership for learning in higher education: the student perspective. Educational Management Administration \& Leadership, 1-25 
Rienties, B., Brouwer, N. \& Lygo-Baker, S. (2013). The effects of online professional development on higher education teachers' beliefs and intentions towards learning facilitation and technology. Teaching and Teacher Education, 29, 122-131.

Rogers, D. L. (2000). A paradigm shift: Technology integration for higher education in the new millennium. AACE Journal, 1(13), 19-33.

Skinner, B. F. (1960). Teaching machines. The Review of Economics and Statistics, 189-191.

Smerdon, B., Cronen, S., Lanahan, L., Anderson, J., Iannotti, N. \& Angeles, J. (2000). Teachers' Tools for the 21st century: A report on teachers' use of technology. Statistical Analysis Report.

Steinweg, S. B., Williams, S. C. \& Stapleton, J. N. (2010). Faculty use of tablet PCs in teacher education and K-12 settings. TechTrends, 54(3), 54-61.

Stensaker, B., Maassen, P., Borgan, M., Oftebro, M. \& Karseth, B. (2007). Use, updating and integration of ICT in higher education: Linking purpose, people and pedagogy. Higher Education, 54(3), 417433.

Tront, J. G. (2007). Facilitating pedagogical practices through a large-scale tablet PC deployment. IEEE Computer, 40(9), 62-68.

Van Oostveen, R., Muirhead, W. \& Goodman, W. M. (2011). Tablet PCs and reconceptualizing learning with technology: a case study in higher education. Interactive Technology and Smart Education, 8(2), 78-93.

Weaver, A. \& Prey, J. (2007). Guest editors' introduction: Tablet PC technology-the next generation. Computer, 40(9), 32-33.

Weber, E. K. (2013). An analysis of faculty development levels of use outcomes at one higher education institution. (Unpublished dissertation), University of Dayton. 